\title{
ORGANIZAÇÃO DO TRABALHO NA ALFABETIZAÇÃO: APONTAMENTOS DOCENTES A PARTIR DO PNAIC ${ }^{1}$
}

\author{
ORGANIZATION OF WORK IN LITERACY: TEACHING NOTES FROM THE PNAIC
}

\section{ORGANIZACIÓN DEL TRABAJO EM ALFABETIZACIÓN: APUNTES DOCENTES DEL PNAIC}

Tatiana Andrade Fernandes de Lucca ${ }^{2}$

Andréia Osti ${ }^{3}$

\begin{abstract}
Resumo: Discute-se a organização do trabalho pedagógico no processo formativo do PNAIC. A pesquisa ocorreu por meio de entrevistas semiestruturadas e os resultados evidenciam que as docentes possuem um olhar positivo para a formação, sendo que elencam aspectos contributivos para sua prática em sala de aula, bem como para a reflexão de suas ações. Assim, destacam como contribuições do PNAIC as mudanças na organização das propostas educativas, bem como o conhecimento dos direitos de aprendizagem para a alfabetização e a sua consideração nos planejamentos dos docentes. Por fim, entende-se a relevância do PNAIC no cenário brasileiro, no entanto, reconhece-se que outras ações são necessárias para alcançar melhorias nos desempenhos dos alunos.
\end{abstract}

Palavras-chave: Formação de professores; ensino; currículo.

Abstract: It discusses the organization of the pedagogical work carried out in the training process of the PNAIC. The research took place through semi-structured interviews and the results show that the teachers have a positive look at training, listing aspects that contribute to their practice in the classroom, as well as to the reflection of their actions. Learning rights are pointed out as the element that was appropriated by them and that supported the planning and organization of educational proposals. Finally, we understand the relevance of the PNAIC in the Brazilian scenario, however, it is recognized that other actions are necessary to achieve improvements in student performance.

Keywords: Teacher training; teaching; curriculum.

Resumen: Se discute la organización del trabajo pedagógico en el proceso de formación del PNAIC. La investigación se realizó a través de entrevistas semiestructuradas y los resultados muestran que los docentes tienen una mirada positiva a la formación, enumerando aspectos que contribuyen a su práctica en el aula, así como a la reflexión de sus acciones. Los derechos de aprendizaje se señalan como el elemento del que se apropiaron y que apoyó la planificación y organización de las propuestas educativas. Finalmente, se comprende la relevancia del PNAIC en el escenario brasileño, sin embargo, se reconoce que son necesarias otras acciones para lograr mejoras en el desempeño de los estudiantes.

Palabras clave: Formación de profesores; enseñando; currículo.

\section{Introdução}

Este trabalho aborda a discussão da temática da organização do trabalho na alfabetização no âmbito do programa formativo do Pacto Nacional pela Alfabetização na Idade Certa (PNAIC). O PNAIC foi um programa de iniciativa do Governo Federal, criado em 2012, que tinha como

\footnotetext{
${ }^{1}$ Esta pesquisa contou com o apoio da CAPES - Código de Financiamento 001.

${ }^{2}$ UNESP - Rio Claro.

${ }^{3}$ UNESP - Rio Claro.
} 
principal objetivo garantir a alfabetização de crianças até o $3^{\circ}$ ano do Ensino Fundamental. Assim, houve o estabelecimento de parceria com os estados e municípios, bem como com Instituições de Ensino Superior (IES), que atuaram na formação dos agentes que, posteriormente, seriam responsáveis pela formação dos professores alfabetizadores. O PNAIC consistiu em um programa com diversas ações, envolvendo os entes supracitados. Não obstante, entende-se que um dos eixos mais representativos foi a formação continuada oferecida aos professores alfabetizadores.

Esse processo ocorreu por meio um curso, no ano de 2013, com carga horária anual de 120 horas, com encontros presenciais que, de acordo com o documento (BRASIL, 2012a) ocorreriam no município do professor alfabetizador. Os responsáveis por ministrar o curso para esses professores alfabetizadores eram os denominados orientadores de estudo, que eram, na realidade, professores pertencentes ao quadro da rede ensino. As IES eram incumbidas pela formação desses orientadores.

Caracterizada a forma como estava prevista a realização do processo formativo do professor alfabetizador, pode-se identificar o envolvimento de outros sujeitos neste processo, naquilo que se pode denominar como formação em "efeito cascata". Isso porque o sujeito responsável pela formação do professor também deveria estar envolvido em outro processo formativo para exercer sua função.

O PNAIC é embasado por quatro princípios centrais, sendo que o primeiro deles corresponde à temática do planejamento, uma vez que preconiza que o Sistema de Escrita Alfabética (SEA) é complexo e, por isso, exige um ensino sistemático e problematizador (BRASIL, 2012a). Desse modo, entende-se que a temática da organização e planejamento do ensino consistem em elementos centrais do programa, dentre as outras perspectivas discutidas pela proposta, tais como: a alfabetização e o letramento, a heterogeneidade dos conhecimentos em sala de aula, a ludicidade e a interdisciplinaridade.

\section{A abordagem do planejamento no PNAIC}

Entende-se que o planejamento consiste em um significativo eixo do trabalho docente. Zasso, Silva e Borges (2020) o consideram uma ação estruturante da prática pedagógica, que concretiza o objetivo estipulado pelo professor e expressa as suas intencionalidades. Ademais, compreende-se que esse dispositivo também expõe as concepções que o docente possui sobre os processos educativos, bem como sobre o objeto de ensino sobre o trabalho que realiza. No contexto deste estudo, portanto, o planejamento pode revelar as concepções teóricas e metodológicas acerca da alfabetização.

O PNAIC aborda a complexidade do processo de alfabetização, destacando que tal aprendizagem mobiliza diferentes habilidades e competências, que não se restringem à compreensão do funcionamento do sistema de escrita alfabética. Sendo assim, o planejamento é recorrentemente mencionado como um meio de o alfabetizador organizar, junto aos estudantes, as aprendizagens diversas necessárias, de modo a contemplar essa multiplicidade que compõem o processo de alfabetização.

O caderno de apresentação (BRASIL, 2012a), por exemplo, ao discorrer sobre a organização dos tempos escolares, destaca a necessidade do estabelecimento de momentos para o planejamento das propostas. Nesta seção também pode-se identificar a articulação que o PNAIC realiza entre a concepção de alfabetização adotada e a organização do trabalho pedagógico, considerando as habilidades que precisam ser trabalhadas nesse período. Assim, destaca:

[...] a necessidade de um trabalho intencional, com aproveitamento máximo da carga horária semanal em que a criança permanece na escola. $O$ planejamento sistemático, com vistas a garantir aprendizagens, evita 
desperdício de tempo. Frequentemente, a falta de planejamento prévio faz com que os docentes improvisem atividades pouco produtivas em relação às prioridades curriculares (BRASIL, 2012a, p. 19).

Há ênfase, portanto, quanto à consideração do que é necessário trabalhar nos anos referentes à alfabetização e a organização de tais aprendizagens no tempo disponível. Alguns dos cadernos direcionados aos professores participantes retratam essa temática de forma mais expressiva, enquanto outros expõem essa discussão de modo menos enfático. Nesses materiais encontram-se os pressupostos que embasam a discussão sobre o planejamento pretendida pelo PNAIC.

Uma das temáticas que perpassa os cadernos de formação é a interdisciplinaridade, entendida como um direito do educando. Assim, a discussão mobiliza a reflexão da possibilidade de alfabetizar as crianças por meio das diferentes áreas do conhecimento, bem como ocasionar que essa aprendizagem tenha significado aos estudantes. Outro tema que fundamenta essa discussão diz respeito à avaliação diagnóstica como um recurso que embase o planejamento do professor. Defende-se a ideia de que a organização do trabalho precisa considerar as aprendizagens infantis, ponderando, dessa forma, o que os estudantes já sabem sobre o tema e o que ainda precisa ser aprofundado ou trabalhado com mais ênfase.

No âmbito da consideração dos conhecimentos prévios dos alunos, o PNAIC propõe e oferece subsídios para a discussão das metas e objetivos na alfabetização. Tal discussão está fundamentada nos direitos de aprendizagem propostos para as diversas áreas do conhecimento. Esses direitos apresentam os conhecimentos que podem ser trabalhados a cada ano do ciclo de alfabetização e ainda contêm a indicação daquilo que pode ser introduzido naquele ano, ou aprofundado, para posterior retomada nos anos seguintes e itens que devem consolidados naquele ano. Apesar de evidenciar essas indicações explícitas quanto à organização do trabalho na alfabetização, o material do PNAIC não considera tal instrumento uma prescrição aos professores, já que entende que aborda: "[...] alguns conhecimentos e capacidades estão descritos e podem ser postos como pontos de partida para o estabelecimento do debate" (BRASIL, 2012b, p. 31).

Além desse instrumento de referência para o planejamento, os cadernos de formação também oferecem os denominados quadros de monitoramento, que consistem em dispositivos que auxiliam o professor no acompanhamento das aprendizagens dos educandos, a partir do é pressuposto nos direitos de aprendizagem. Assim, apesar de esse material constar como um exemplo de como é possível efetuar o acompanhamento, ele exemplifica como o PNAIC integra a ação avaliação diagnóstica ao planejamento docente e a relação mútua entre ambos.

Os cadernos, de modo geral, mencionam a necessidade da diversificação de estratégias e dos tipos de atividades oferecidos, como um meio de contemplar as diferentes habilidades supracitadas nos direitos de aprendizagem. Nos cadernos da Unidade 4, que discutem o lúdico, essa temática é ainda abordada por meio da orientação quanto à diversificação dos agrupamentos de alunos segundo critérios específicos, que podem ocorrer mediante à inserção de materiais, tais como os jogos de alfabetização.

$\mathrm{Na}$ Unidade 6, os cadernos referenciam as formas como pode ocorrer a organização do trabalho pedagógico, por meio das sequências didáticas e dos projetos didáticos. Entende-se que essas formas permitem contemplar a interdisciplinaridade, bem como vincular as necessidades de aprendizagem dos alunos. Ademais, possibilitam um trabalho contextualizado com a escrita e a inserção das práticas de letramento. Os projetos e sequências didáticas também articulam o interesse infantil por determinadas temáticas e ações.

O Quadro 1 consiste em um recorte da ementa do curso do PNAIC do ano 2013, no qual é possível observar como a temática do planejamento e da organização do trabalho 
pedagógico perpassa o material de formação, por meio das unidades dos cadernos que abordam esse tema, com a sua respectiva carga horária:

\begin{tabular}{|l|l|}
\hline \multicolumn{1}{|c|}{ Unidade } & \multicolumn{1}{c|}{ Temas abordados } \\
\hline Unidade 2 (8 horas) & $\begin{array}{l}\text { Planejamento do ensino na alfabetização na perspectiva do } \\
\text { letramento, integrando diferentes componentes curriculares [...]; a } \\
\text { importância de diferentes recursos didáticos na alfabetização[...]. }\end{array}$ \\
\hline $\begin{array}{l}\text { Unidade 4 (12 } \\
\text { horas) }\end{array}$ & $\begin{array}{l}\text { A sala de aula como ambiente alfabetizador: a exposição e } \\
\text { organização de materiais que favorecem o trabalho com a } \\
\text { alfabetização[...] atividades diversificadas em sala de aula para } \\
\text { atendimento às diferentes necessidades das crianças[...]; estratégias } \\
\text { de inclusão de crianças com deficiência visual, auditiva, motora e } \\
\text { intelectual, bem como crianças com distúrbios de aprendizagem nas } \\
\text { atividades planejadas. }\end{array}$ \\
\hline $\begin{array}{l}\text { Unidade 6 (12 } \\
\text { horas) }\end{array}$ & $\begin{array}{l}\text { Projetos e sequências didáticas na alfabetização, integrando } \\
\text { diferentes componentes curriculares (Matemática, Ciências, } \\
\text { História, Geografia, Arte); o papel da oralidade, da leitura e da } \\
\text { escrita na apropriação de conhecimentos de diferentes áreas do } \\
\text { saber escolar. }\end{array}$ \\
\hline
\end{tabular}

Quadro 1: Ementa do curso de 2013 com foco na temática da organização do trabalho pedagógico Fonte: (BRASIL, 2012a, p. 33). Adaptado pelas autoras.

Assim, observa-se a articulação das diferentes temáticas que foram abordadas no PNAIC e a sua influência para a organização do trabalho pedagógico na alfabetização. Isto posto, entende-se que o programa discutiu e ofereceu embasamentos que proporcionaram reflexões aos participantes quanto às formas de se organizar o processo de alfabetização, considerando a complexidade desta aprendizagem. Convém destacar que um dos princípios formativos do programa correspondia ao objetivo de provocar mudanças nas práticas docentes. Sendo assim, entende-se que essas discussões, bem como os dispositivos apresentados (tais como os direitos de aprendizagem e os quadros de monitoramento) correspondem a essa tentativa de estimular mudanças na ação docente, por meio das temáticas discutidas, embasadas nos princípios do programa.

Considerando o investimento do PNAIC nesse tema específico, por meio de diversas perspectivas, bem como a compreensão de que mudanças nas práticas docentes dependem de fatores diversos, este trabalho tem como objetivo apresentar dados de uma pesquisa na qual as participantes ressaltaram a relevância da discussão do planejamento e da organização do trabalho em sala de aula a partir do processo formativo do PNAIC.

\section{Percurso metodológico}

O estudo foi realizado mediante pesquisa qualitativa, que teve como objetivo investigar quais eram as contribuições da formação do PNAIC para um grupo de professoras alfabetizadoras que fizeram o curso em 2013. Participaram dez professoras de um município do interior de São Paulo, da mesorregião de Piracicaba. Quanto ao perfil das docentes, todas lecionavam nos iniciais do Ensino Fundamental no período de realização da pesquisa. As idades das professoras variavam entre 31 e 51 anos. 
Sobre o tempo de magistério, observa-se que a maioria possui uma ampla experiência como professora da educação básica, tendo entre 6 e 30 anos de docência. Em relação ao tempo em que estão no período da alfabetização, isto é, nos três primeiros anos do Ensino Fundamental, enfatiza-se a atuação das participantes nesse processo, entre 5 e 24 anos, sendo que algumas delas trabalham diretamente com a alfabetização desde o início da carreira. Todas possuem ensino superior completo. Das dez participantes, quatro tinham formação anterior no magistério. Em relação a cursos de pós-graduação, oito tinham especialização, especialmente na área da alfabetização e letramento, uma era mestra e outra estava cursando o mestrado.

A coleta de dados ocorreu por meio da realização de entrevistas individuais semiestruturadas. Esse instrumento estava organizado em oito questões, que tratavam sobre diferentes aspectos do processo formativo, dentre eles, as contribuições e modificações para as práticas percebidas pelas professoras a partir da participação no PNAIC. Após a realização das entrevistas, os dados foram organizados e analisados, tendo como referência a análise de conteúdo de Bardin (1977). Assim, por meio da criação de categorias específicas, obteve-se algumas considerações acerca da experiência do processo formativo para esse grupo de participantes, sendo que aqui destaca-se a relação das professoras com as discussões sobre o planejamento e a organização do trabalho docente. As participantes são identificadas por um $\mathrm{P}$ seguido de um numeral.

\section{As experiências das alfabetizadoras no PNAIC}

Quando questionadas acerca das contribuições do PNAIC, as professoras identificaram diversos elementos, que perpassam desde a distribuição de materiais específicos para a alfabetização, tais como os livros literários e jogos pedagógicos, até as discussões realizadas no curso presencial, com ênfase no trabalho formativo desenvolvido pelo orientador de estudos. $\mathrm{O}$ tema da organização do trabalho pedagógico, que permeia os materiais de formação, também foi objeto de análise pelas participantes e reconhecido como um assunto relevante, que possibilitou reflexões sobre o trabalho docente, bem como modificações em seus fazeres.

Algumas delas relataram temas específicos abordados na formação, que lhes permitiram refletir sobre esses aspectos, como por exemplo, a professora P2, que menciona a discussão sobre a complexidade do sistema de escrita alfabética, bem como a avaliação e os quadros de acompanhamento sugeridos para o registro do desempenho dos alunos: "[...] ofereceu aos professores um material didático rico e inovador. Houve grande reflexão sobre a complexidade da aprendizagem do Sistema de Escrita Alfabética, meios para avaliação e monitoramento do processo de ensinoaprendizagem". A professora P5 cita a interdisciplinaridade, a ludicidade e a inclusão como temáticas relevantes aludidas no curso e que embasaram suas reflexões sobre a prática em alfabetização:

[...] foi um dos divisores de águas. [...] porque primeiro o professor ganhou, foi valorizado para fazer esse curso. Nunca foi feito isso. E segunda coisa, foi um divisor de águas porque se delimitou os direitos de aprendizagem, que não eram estabelecidos antes, nem nos parâmetros, nem por ocasião do Letra e Vida. [...] O Pacto falou de interdisciplinaridade, falou de intertextualidade. [...] eu acho que discute bem, inclusive tem muitos textos, questão da ludicidade, questão da inclusão. [...] Você tem uma visão mais respeitosa sobre infância. Foi discutido, inclusive, conceitos de infância (Professora P5).

A possibilidade de reflexão das práticas a partir da experiencia do PNAIC é também comentada pela professora P8, que considera que por meio dessa proposta pode rever suas ações e retomar outras que, de acordo com ela, estavam dormentes: “[...] retomando práticas que eu 
sabia serem de grande valia para a alfabetização das crianças e lapidando algumas outras práticas, deixando essas práticas mais eficazes" (Professora P8).

A partir desses excertos entende-se que o PNAIC, ao inserir tais temáticas para discussão junto aos alfabetizadores, propiciou momentos em que esses profissionais pudessem analisar suas ações no âmbito do ensino, por meio de um contexto embasado em concepções sobre aprendizagem e alfabetização. Ressalta-se que essa reflexão a qual cita algumas das participantes consiste em um dos objetivos da proposta. No caderno Formação de professores no Pacto Nacional pela Alfabetização na Idade Certa (BRASIL, 2012b) define-se que: “[...] trabalhar com os profissionais em serviço é, sobretudo, administrar diferentes saberes e procedimentos que os levem a um novo pensar e fazer a partir de diferentes processos, considerando os percursos individuais e sociais (BRASIL, 2012b, p 12).

Assim, diferentemente da formação inicial, a formação continuada envolve o trabalho junto a profissionais atuantes na área e que, portanto, possuem saberes e conhecimentos específicos sobre o tema. Desse modo, ainda que a proposição de mudanças ou novas estratégias para obtenção de resultados desejáveis (no caso, a alfabetização dos alunos na idade certa) seja uma das metas desse tipo de proposta, a formação continuada também atua na mobilização dos saberes dos participantes, conduzindo-os em um processo de reflexão sobre esses fazeres, a partir do embasamento proposto. Assim, compreende-se que nem sempre as mudanças foram pontuais e observáveis nas práticas dessas professoras. Mas, de certa forma, o PNAIC viabilizou que refletissem sobre determinados aspectos de sua profissão.

Em relação ao tema da organização do trabalho pedagógico, evidenciaram que a formação proporcionou novas formas de elaborar suas aulas, bem como conhecer novas estratégias e atividades. Em consonância com tais assertivas Cardoso e Cardoso (2016) também assinalam que os professores ressaltam mudanças na prática em relação à organização das aulas e à adequação dos conteúdos, bem como na utilização de materiais disponibilizados pelo programa: "O curso causou impacto na prática pedagógica, porque trouxe aprendizagem, novas atividades e diferentes formas de trabalhar com alunos, a exemplo da leitura e do planejamento de aulas [...] trazendo mudanças na organização didática das aulas" (CARDOSO; CARDOSO, 2016, p. 102).

As professoras P1, P3 e P4 apontam mudanças pontuais em seu fazer docente, como por exemplo, a compreensão da importância das sequências didáticas, que era um tema abordado nos cadernos da Unidade 5 do material, a construção da rotina e a análise do texto bem escrito. A professora P3 menciona que o PNAIC possibilitou mudanças na abordagem dos conteúdos. Os excertos a seguir expõem as diferentes perspectivas das professoras quanto a essas temáticas:

P1: [...] passei a refletir sobre a importância da rotina, sequências didáticas e análise do texto bem escrito.

P3: Talvez, tenha me auxiliado na forma de abordar determinados conteúdos, mas a prática, no geral, creio que não muito.

P4: Eu já trabalhava bastante com jogos e histórias, mas as leituras teóricas reforçaram a visão da importância dessas práticas.

A participante P5 também relata as mudanças que o programa provocou em sua forma de planejamento, ao incorporar em seu plano de trabalho as orientações do PNAIC. Não obstante, infere-se que essa mudança não ocorreu apenas no ano de realização do curso, mas tal forma de organizar o planejamento foi incorporada nos anos seguintes: "Se você pega o material, tudo que eu preciso, às vezes, inclusive tenho um no armário, eu recorro ao material do Pacto. Fiz meu planejamento tudo baseado, se pegar meu plano, está baseado nos direitos de aprendizagem".

O elemento mais citado pelas participantes foi o estabelecimento dos direitos de aprendizagem. Para seis das dez entrevistadas esse documento consistiu na contribuição mais 
consistente do programa, bem como ofereceram indícios de que houve apropriação de tal dispositivo em suas práticas e planejamentos. No caderno de apresentação do PNAIC tem-se uma referência ao estabelecimento desses direitos, elucidando que no curso,

[...] serão desenvolvidas ações que contribuam para o debate acerca dos Direitos de Aprendizagem das crianças do ciclo de alfabetização: para os processos de avaliação e acompanhamento da aprendizagem das crianças, para o planejamento e avaliação das situações didáticas; para o conhecimento e uso dos materiais distribuídos pelo Ministério da Educação, voltados para a melhoria da qualidade do ensino no ciclo da alfabetização" (BRASIL, 2012a, p. 40).

Desse modo, entende-se que há uma relação entre a compreensão da validade e contribuição dos direitos de aprendizagem e a percepção de que, a partir do PNAIC, houve mudanças e mais reflexões acerca da elaboração do planejamento e da organização do trabalho docente. Logo, inferese que o estudo e maior atenção para esse conteúdo da formação pode ter contribuído para esse olhar mais atento à organização dos conteúdos e à preparação das aulas, colaborando para que as professoras tivessem o cuidado em considerar os aspectos elencados nos direitos de aprendizagem.

Alguns comentários das participantes assinalam a relevância dos direitos de aprendizagem, como ilustram as professoras P6 e P9: P6: "[...] ele mostra pra gente os direitos de aprendizagem da criança, assim, de uma forma mais detalhada e situa a gente, atualiza". P9: "O que valeu a pena foi os Direitos de Aprendizagem [...] agora esses Direitos de Aprendizagem clarearam até onde eu poderia ir[...]". As entrevistadas também observaram que modificaram suas práticas no que diz respeito à preparação de aulas.

Desse modo, considera-se que tais mudanças não são ocasionais, isto é, elas são esperadas e propostas pelo programa de formação. Conforme assinala Klein (2015), os cadernos têm um discurso que mobilizam os professores a refletir sobre sua prática, se a proposta de atividades é adequada ou não e se os recursos utilizados são os mais apropriados para a aprendizagem dos alunos. A autora afirma que "Por meio das orientações propostas nos materiais, o/a professor/a representado/a como reflexivo/a é instigado a pensar se o seu saber pode ser modificado, trocado, reconstruído, refeito" (KLEIN, 2015, p. 90).

Pelos excertos das entrevistas, percebe-se que os direitos de aprendizagem foram apropriados de maneiras distintas pelas professoras, considerando suas trajetórias e experiências na alfabetização. A professora P6, por exemplo, comenta a contribuição desse recurso para a organização do seu trabalho: "[...] na minha prática foi na questão da organização [...] eu já comecei a ter uma organização, o que apresentar primeiro, o que eu tinha que aprofundar mais o conteúdo, então essas partes ficaram um pouco mais claras para mim, porque eu era iniciante" (Professora P6).

A professora $\mathrm{P} 9$, que possuía uma significativa experiência em alfabetização quando participou do curso, também destaca a relevância dos direitos de aprendizagem enquanto um embasamento para suas ações: "Como eu já sou, já tenho bastante tempo de carreira, então a gente já tem uma base de trabalho, agora esses direitos de aprendizagem vieram mostrar, clareou até onde eu poderia ir. Mas que acrescentou para meu trabalho ficar melhor" (Professora P9).

Desse modo, esses dois trechos ilustram as experiências de professoras que estavam vivenciando momentos distintos em suas carreiras, uma iniciante e a outra experiente, e que encontraram nos direitos de aprendizagem um fundamento para o planejamento das aulas e para a organização dos conteúdos na alfabetização, tendo a clareza das aprendizagens que competiam a cada ano. Essas falas evidenciam, portanto, a apropriação desse recurso proposto pelo programa.

Ademais, demonstram que os direitos de aprendizagem foram um documento relevante para esclarecer quais eram as metas do ano e quais eram as aprendizagens importantes, sendo, dessa forma, um referencial que interferiu e influenciou em seus planejamentos. Nesse âmbito, Frade 
(2020) entende que esses aspectos propostos pelo PNAIC consistiram em avanços para as referências curriculares para alfabetização, mesmo sem equivaler a um documento mandatário.

Morais, Silva e Nascimento (2020) argumentam que ausência de orientações curriculares suscitam uma variedade de práticas desarticuladas e a falta de progressão entre as aprendizagens. Desse modo, entende-se que as participantes desse processo formativo encontraram nos direitos de aprendizagem as orientações quanto aos conteúdos pertinentes à alfabetização, especialmente a progressão das aprendizagens entre os anos, uma vez que ressaltaram o esclarecimento proporcionado pelo documento quanto ao que competia ao trabalho de cada ano no ciclo da alfabetização. Além do mais, entende-se que esses direitos também viabilizaram uma organização em comum, entre os alfabetizadores, quanto às expectativas das aprendizagens dos estudantes, tomando o documento como uma referência.

Portanto, os professores compreendem que o PNAIC proporcionou contribuições e modificações pontuais em sua prática, isto é, que ao participar do curso conseguiram introduzir em suas aulas elementos estudados e discutidos no programa. Outrossim, observa-se que as reflexões e mudanças acerca da organização do trabalho pedagógico e do planejamento não se restringiram aos temas propostos pelo programa nesse âmbito, como as sequências didáticas e a interdisciplinaridade, por exemplo. Mas, partindo dos direitos de aprendizagem e dos conteúdos previstos nesse dispositivo, as professoras realizaram uma reflexão sobre o seu trabalho na alfabetização, bem como identificaram esse recurso como um embasamento para o seu planejamento e para a organização das atividades. Com isto, infere-se que as professoras têm um olhar positivo para o programa e para suas contribuições quanto ao seu trabalho na área da alfabetização. Não obstante, esses relatos decorrem de um processo reflexivo sobre a formação e suas possibilidades de colaboração para seu fazer docente.

Acerca desse processo reflexivo, as professoras também oferecem indícios que possibilitaram ponderar sobre a efetividade e as contribuições das formações continuadas para o seu desenvolvimento profissional. No decorrer das entrevistas, além de mencionar os conteúdos abordados no curso, elas também apontaram para as relações que se estabeleceram nesta proposta, indicando as trocas de saberes e experiências entre os pares e os formadores, como demonstra, por exemplo, a Professora P6: “[...] no curso eu lembro que tinha muitas rodas de conversa, muita troca de experiência [...] então, ajudava também". Portanto, ressaltam as vivências e essas trocas como elementos relevantes em seus processos formativos. Essas observações expõem o reconhecimento das professoras quanto à legitimidade da troca de experiências e saberes enquanto um momento significativo para sua formação e para a aprendizagem de aspectos específicos da docência, destacando a relevância do PNAIC em proporcionar tal espaço de discussão entre os alfabetizadores.

No entanto, também demarcam a compreensão de que a formação continuada, tal como o PNAIC, não responde por toda a mudança necessária na escola e, em especial, para a discussão acerca das práticas em alfabetização: “P6: Não é assim também, fiz o curso e estou craque!”. Esse excerto da professora P6, acerca da sua vivência no curso, assinala o entendimento de que há outros fatores envolvidos no exercício da docência e no contexto escolar.

Ademais, é expressivo que $20 \%$ das participantes não compreendam que o PNAIC lhes ofereceu contribuições para suas práticas: P3: "Talvez, tenha me auxiliado na forma de abordar determinados conteúdos, mas a prática, no geral, creio que não muito"; P10: "Mudança, mesmo, praticamente nenhuma". Essas falas permitem propor algumas inferências quanto às expectativas das professoras em relação ao curso e a discrepância quanto ao que foi vivenciado. Além disso, também podem sugerir, como mencionado pelas professoras P9 e P10, que o PNAIC não atendeu às necessidades formativas por elas esperadas: P9: "A formação foi boa, mas o caderno não era aprofundado, não fez um bom aprofundamento, um bom estudo"; 
P10: [...] eles pegam uma literatura, várias literaturas, analisam, elaboraram o texto em duas folhas, com vários autores citados e quando você vai na bibliografia você vê dez autores citados para falar um assunto em duas folhas. Então, se você for considerar enquanto aprofundamento de estudo, não... Superficial.

As falas supracitadas exprimem que as professoras P9 e P10 buscaram nos materiais de formação aprofundamentos teóricos e didáticos para suas práticas, não obstante, consideraram que o material não oferecia um embasamento razoável. É a partir dessas ponderações que se compreende que os professores, ao ingressarem nesses processos formativos, possuem expectativas de aprendizagem, considerando suas experiências com a temática, bem como suas necessidades de formação, ou ainda, o interesse em aprofundar determinado assunto. Sendo assim, entende-se que o PNAIC, ao propor uma formação ampla, para todo o território nacional, mobilizou discussões que podem não ter sido do interesse de todos os participantes, especialmente de alfabetizadores mais experientes, como é caso das entrevistadas P9 e P10.

Outrossim, como evidenciam Barros-Mendes e Gomes (2019), o processo de alfabetização nas escolas públicas brasileiras envolvem aspectos para além da prática docente, mas que abrangem a realidade e as condições vivenciadas por professores e alunos nesses processos de aprendizagem. Assim, os autores ressaltam que os contextos de infraestrutura das escolas e o acesso à materiais didáticos impactam nos resultados de aprendizagem obtidos pelos alunos, no entanto, ponderam que tal debate é negligenciado nas políticas e ações empreendidas nessa área. Desse modo, entendese a relevância de as políticas públicas em educação pautarem discussões que mobilizem mudanças não apenas nas práticas docentes, mas também nas infraestruturas das escolas e nas realidades nas quais os professores atuam, como condições para a melhoria da educação brasileira.

\section{Considerações finais}

A pesquisa realizada evidenciou as contribuições que o PNAIC proporcionou às professoras, especialmente no que diz respeito às reflexões e modificações no planejamento das aulas e na organização do trabalho pedagógico. Sabe-se que a alfabetização é um tema no qual o Brasil ainda enfrenta percalços, assim, entende-se a relevância desse programa, em âmbito nacional, ao proporcionar discussões sobre a temática junto aos alfabetizadores. Ademais, esse processo formativo discutiu não apenas referenciais pertinentes à alfabetização, mas abrangeu aspectos sobre o trabalho didático-pedagógico realizado pelos professores.

Outrossim, os dados também revelam a complexidade dos processos de formação continuada, uma vez que se direcionam à profissionais atuantes na área e que, portanto, possuem saberes e conhecimentos sobre o tema. Bem como necessidades formativas específicas, que estão relacionadas às suas trajetórias e experiências vivenciadas no seu trabalho cotidiano. Desse modo, o desafio consiste em mobilizar esses conhecimentos e saberes, assim como atuar e proporcionar reflexões que possibilitem aos participantes novas formas de pensar e agir em seus espaços de atuação.

Entende-se que os direitos de aprendizagem, estipulados nos materiais de formação do PNAIC, consistiram em um documento de referência para as participantes na elaboração de seus planejamentos, bem como na consideração da progressão das aprendizagens dentro do ciclo de alfabetização. Assim, a despeito de outros assuntos que também contribuíram para a reflexão sobre a organização do trabalho pedagógico, as professoras evidenciaram esse instrumento como um embasamento para suas ações.

Por fim, considerando a relevância do PNAIC no cenário nacional, depreende-se que os processos formativos podem melhor contribuir para o desenvolvimento profissional dos professores se partirem das suas realidades e necessidades formativas (LUCCA; OSTI, 2019). 
Bem como os considerarem como sujeitos dessa formação, como profissionais que possuem saberes e experiências a serem compartilhados.

Ademais, reconhece-se que avanços na área da alfabetização, especialmente nas aprendizagens dos estudantes, não decorrem apenas das mudanças advindas nos processos de formação de professores. Por sua vez, envolvem os desafios que já estão postos para a educação básica brasileira, como a melhoria das condições de trabalho dos docentes, a valorização desses profissionais, o investimento nas infraestruturas das escolas, o acesso à recursos didáticos de qualidade, dentre outros.

\section{Referências}

BARDIN, L. Análise de conteúdo. Lisboa: Edições 70, 1977.

BRASIL. Ministério da Educação. Secretaria de Educação Básica. Diretoria de Apoio à Gestão Educacional. Pacto Nacional pela Alfabetização na Idade Certa: caderno de apresentação. Brasília: MEC; SEB, 2012a.

BRASIL. Ministério da Educação. Secretaria de Educação Básica. Diretoria de Apoio à Gestão Educacional. Pacto Nacional pela Alfabetização na Idade Certa: formação de Professores no Pacto Nacional pela Alfabetização na Idade Certa. Brasília: MEC, SEB, 2012b.

BARROS-MENDES, A.; GOMES, R. A alfabetização e as condições para alfabetizar. Revista Brasileira de Alfabetização - ABAlf, Belo Horizonte, v. 1, n. 10 [edição especial], p. 112-116, jul./dez. 2019.

CARDOSO, C. J.; CARDOSO, A. L. J. Formação continuada no contexto do Pacto Nacional pela Alfabetização na Idade Certa: alinhamento entre práticas, princípios formativos e objetivos. Práxis Educativa, v. 11, n. 1, p. 89-106, 2016.

FRADE, I. C. A. S. Palavra aberta - BNCC e a alfabetização em duas versões: concepções e desafios. Educação em Revista [online], Belo Horizonte, v. 36, p. 1-15, 2020. Disponível em: https://www.scielo.br/j/edur/a/59gyKsrp4vJVknvWtWpRNsH/?lang=pt. Acesso em: 06 dez. 2021.

KLEIN, J. M. Representações e identidades docentes nos cadernos de formação do programa Pacto Nacional pela Alfabetização na Idade Certa (PNAIC). 2015. 138f. Dissertação (Mestrado em Educação) - Universidade Luterana do Brasil, Canoas, 2015.

LUCCA, T. A. F.; OSTI, A. Contribuições e limitações do Pacto Nacional pela Alfabetização na Idade Certa: um estudo com professores alfabetizadores. Revista de Educação PUCCampinas, v. 24, n. 2, p. 175-193, 2019.

MORAIS, A. G.; SILVA, A.; NASCIMENTO, G. S. Ensino da notação alfabética e práticas de leitura e escrita na educação infantil: uma análise das três versões da Base Nacional Comum Curricular. Rev. Bras. Educ. [online], v. 25, p. 1-25, 2020. Disponível em: https://www.scielo.br/j/rbedu/a/xN3QNBZWYxKpDWff35hBhMr/abstract/?lang=pt.

Acesso em: 06 dez. 2021. 
ZASSO, S. M. B., SILVA, P. P.; BORGES, D. S. Planejamento das aulas no cotidiano da alfabetização: práticas, perspectivas e desafios. Revista Entreideias: Educação, Cultura e Sociedade, Salvador, v. 9, n. 3, p. 151-171, set./dez. 2020.

\section{Sobre as autoras}

Tatiana Andrade Fernandes de Lucca. Mestra em Educação pela UNESP-Rio Claro. Doutoranda em Educação pela UNESP-Rio Claro. Professora da Educação Básica na Prefeitura Municipal de Rio Claro.

E-mail: tatiana.lucca@unesp.br.

Andréia Osti. Professora do Departamento de Educação da Universidade Estadual Paulista (UNESP) credenciada junto ao Programa de Pós-Graduação em Educação da UNESP de Rio Claro. Doutora em Educação (2010) pela Faculdade de Educação da Universidade Estadual de Campinas (UNICAMP), onde também concluiu os cursos de Mestrado em Educação (2004). Coordena o Grupo de Estudos e Pesquisas em Representações, Aprendizagem, Leitura e Escrita - GEPRALE, credenciado junto ao CNPq desde 2017.

E-mail: andreia.osti@unesp.br. 